Original Article

\title{
Reactive oxygen species partially mediate high dose angiotensin II-induced positive inotropic effect in cat ventricular myocytes
}

\author{
Alejandra M. Yeves, Claudia I. Caldiz, Ernesto A. Aiello, María C. Villa-Abrille, Irene L. Ennis * \\ Centro de Investigaciones Cardiovasculares, Facultad de Ciencias Médicas, UNLP-CONICET, Argentina
}

\section{A R T I C L E I N F O}

\section{Article history:}

Received 25 November 2014

Received in revised form 21 January 2015

Accepted 22 January 2015

\section{Keywords:}

Angiotensin II

Inotropism

Reactive oxygen species

NHE-1

Isolated cardiomyocytes

\begin{abstract}
A B S T R A C T
Background: Reactive oxygen species, such as superoxide, are being increasingly recognized as key components of a vast array of signaling pathways. Angiotensin II is a well-recognized stimulus for superoxide production through NADPH oxidase activation and opening of the mitochondrial ATP-sensitive potassium channels $\left(\mathrm{mK}_{\mathrm{ATP}}\right)$. A role for this mechanism has been proposed to explain several physiological effects of the peptide. The aim of this study was to evaluate the involvement of this mechanism in the inotropic response to $100 \mathrm{nmol} / \mathrm{L}$ angiotensin II.

Methods: Sarcomere shortening and intracellular pH (BCECF-epifluorescence technique) were evaluated in isolated cat ventricular myocytes placed in a perfusion chamber on the stage of an inverted microscope. Myocardial superoxide production was evaluated by the lucigenin quimioluminiscence method.

Results: Angiotensin II (100 nmol/L) increased 70\% sarcomere shortening, effect that was only partially prevented by NADPH oxidase inhibition, $\mathrm{mK}_{\text {ATP }}$ channel blockade or inhibition of the cardiac $\mathrm{Na}^{+} / \mathrm{H}^{+}$exchanger (NHE-1). Moreover, angiotensin II stimulates NHE-1 activity by a NADPH oxidase-dependent mechanism. Myocardial superoxide production was also increased by angiotensin II, and this action was completely prevented either by NADPH oxidase inhibition or $\mathrm{mK}_{\mathrm{ATP}}$ channel blockade.

Conclusions: The positive inotropic response to $100 \mathrm{nmol} / \mathrm{L}$ angiotensin II is due to both ROS/NHE-1 dependent and independent pathways, this being a point of divergence with the signaling previously described to be triggered by lower concentrations of angiotensin II (i.e.: $1 \mathrm{nmol} / \mathrm{L}$ ).
\end{abstract}

(c) 2015 Elsevier Inc. All rights reserved.

\section{Introduction}

Reactive oxygen species (ROS) are produced in all aerobic organisms as a result of incomplete reduction of oxygen during respiration. ROS include free radicals such as superoxide $\left(\mathrm{O}_{2}^{-}\right)$and non-radical compounds such as hydrogen peroxide. ROS are being increasingly recognized as key regulators of an enormous array of intracellular proteins and signaling pathways, both under physiological and pathological conditions (for a review see [1]). The main sources of myocardial ROS are the mitochondrial electron transport chain, NADPH oxidase (NOX), xanthine oxidase and uncoupled nitric oxide synthase. Angiotensin II (Ang II) is a classical stimulus for NOX and superoxide production [2-4]; and a role for this intracellular signaling pathway has been proposed to explain several physiological effects of the peptide $[2,5,6]$.

Both in vascular smooth muscle and myocardium it has been recently described a phenomenon called "ROS-induced ROS release" that seems to play a key role in intracellular signaling $[4,7-9]$. It is proposed that

Abbreviations: ROS, reactive oxygen species; NOX, NADPH oxidase; Ang II, angiotensin II; $\mathrm{mK}_{\mathrm{ATP}}$, mitochondrial ATP-sensitive $\mathrm{K}^{+}$channels; 5-HD, 5-hydroxydecanoate; NHE-1, $\mathrm{Na}^{+} / \mathrm{H}^{+}$exchanger-1; $\mathrm{NCX}, \mathrm{Na}^{+} / \mathrm{Ca}^{2+}$ exchanger; $\mathrm{pH}_{\mathrm{i}}$, intracellular $\mathrm{pH}$.

* Corresponding author at: Centro de Investigaciones Cardiovasculares, Facultad de Ciencias Médicas, UNLP. Calle 60 y 120, 1900, La Plata, Argentina. Tel./fax: + 54221483 $4833 \times 305$.

E-mail addresses: iennis@med.unlp.edu.ar, iennis19@gmail.com (I.L. Ennis).
ROS generated by the membrane NOX induce the opening of mitochondrial ATP-sensitive potassium channels $\left(\mathrm{mK}_{\mathrm{ATP}}\right)$ which in turn triggers the production and release of greater amounts of ROS from the mitochondria with pathophysiological consequences [4,8,9]. In this regard, there is evidence supporting that some effects of Ang II, including kinases activation, are suppressed not only by NOX inhibition with apocynin but also by the blockade of the $\mathrm{mK}_{\text {ATP }}$ with 5-hydroxydecanoate (5-HD) or glibenclamide, reinforcing the importance of the ROS-induced ROS release mechanism. On line with this concept it was demonstrated that the ROS-induced ROS release mechanism underlies the increase in contractility and $\mathrm{Ca}^{2+}$ transient characteristic of the Anrep effect (slow force response to stretch) [10]. Myocardial stretch through the activation of Ang II AT1 receptors stimulates NOX-dependent mitochondrial ROS release and myocardial $\mathrm{Na}^{+} / \mathrm{H}^{+}$exchanger-1 (NHE-1) activity. The NHE-1 is a membrane protein that catalyzes the electroneutral exchange of intracellular protons for extracellular $\mathrm{Na}^{+}$. NHE- 1 hyperactivity leads to intracellular accumulation of $\mathrm{Na}^{+}$, which increase intracellular $\mathrm{Ca}^{2+}$ via the $\mathrm{Na}^{+} / \mathrm{Ca}^{2+}$ exchanger (NCX) and consequently a positive inotropic effect is developed [11]. Although the NHE-1 is relatively quiescent under basal conditions, it is activated by the increase in intracellular $\mathrm{H}^{+}$concentration as well as by several posttranslational modifications usually due to neurohumoral stimulation (i.e.: Ang II, endothelin, and $\beta$-adrenergic stimulation; for a review, see [12]). Moreover, there are several reports supporting a link between ROS and NHE-1 activation 
[13-16]. It is proposed that ROS induce activation of the MEK-ERK1/2p90 ${ }^{\mathrm{RSK}}$ pathway, which increases NHE-1 activity via a phosphorylation process $[16,17]$. Interestingly, the increase in force that takes place during the Anrep phenomenon may be mimicked by $1 \mathrm{nmol} / \mathrm{L}$ exogenous Ang II, a concentration within the range of that found in the interstitial myocardium under physiological conditions [18].

The aim of the present study, which was performed in isolated adult cat ventricular myocytes, was to get insight into the mechanism involved in the positive inotropic effect of Ang II in the concentration that induces the maximal increase in contractility.

\section{Materials and methods}

All procedures followed during this investigation conform to the Guide for the Care and Use of Laboratory Animals published by the US National Institutes of Health (NIH Publication No. 85-23, revised 1996) and the experimental protocol was approved by the Animal Welfare Committee of La Plata School of Medicine. Cats (body weight 3-4 kg) were anaesthetized by intraperitoneal injection of sodium pentobarbital (35 mg/kg body weight) and hearts rapidly excised when plane three of phase III of anesthesia was reached.

Data for each experimental group was obtained from three to six animals.

\subsection{Myocytes Isolation}

Cat ventricular myocytes were isolated according to the technique described previously [19].

\subsection{Sarcomere shortening}

To measure sarcomere length myocytes were placed in a perfusion chamber on the stage of an inverted microscope (Nikon) and continuously superfused with a Krebs-HEPES solution containing $(\mathrm{mmol} / \mathrm{L})$ $\mathrm{NaCl}$ 146.2; HEPES 10; glucosa 11; KCl 4.7; $\mathrm{NaHPO}_{4}$ 0.35; $\mathrm{MgSO}_{4} 1$; $\mathrm{CaCl}_{2} 1.35$ ( $\left.\mathrm{pH} 7.4\right)$ after continuous bubbling with 99.5\% $\mathrm{O}_{2}$. The myocytes were stimulated via 2-platinum electrodes on either side of the bath at $0.5 \mathrm{~Hz}$. The sarcomere length was recorded with specific software (Ion Wizard). The myocytes were observed using a video camera connected to the microscope. The sarcomere length was measured in a determined region of the myocyte at $30{ }^{\circ} \mathrm{C}$ (TC2, Cell micro controls). The software estimated the most frequent sarcomere length in that region using fast Fourier transform analysis (Ion Optix). The average values of the inotropic response were calculated after 10 minutes of incubation with Ang II or no drug. When inhibitors were used, ventricular myocytes were exposed to them from 5 minutes before Ang II stimulus and maintained up to the end of the experiment.

\subsection{Intracellular $\mathrm{pH}\left(\mathrm{pH}_{i}\right)$ measurements}

$\mathrm{pH}_{\mathrm{i}}$ was measured in single isolated myocytes superfused with the Krebs-HEPES solution (bicarbonate free) with an epi-fluorescence system (Ion Optix, Milton, MA) following the previously described BCECF-epifluorescence technique. [19] Briefly, myocytes were incubated at room temperature for $10 \mathrm{~min}$ with $10 \mu \mathrm{mol} / \mathrm{L}$ BCECF-AM followed by 30 min washout. Dye-loaded cells were placed in a chamber on the stage of an inverted microscope (Nikon. TE 2000-U) and continuously superfused with the Krebs-HEPES solution. The myocytes were stimulated via two-platinum electrodes on either side of the bath at $0.5 \mathrm{~Hz}$. Dual excitation ( 440 and $495 \mathrm{~nm}$ ) was provided by a 75-watt Xenon arc lamp and transmitted to the myocytes. Emitted fluorescence was collected with a photomultiplier tube equipped with a band-pass filter centered at $535 \mathrm{~nm}$. The 495 -to- $440 \mathrm{~nm}$ fluorescence ratio was digitized at $10 \mathrm{kHz}$ (ION WIZARD fluorescence analysis software). At the end of each experiment, the fluorescence ratio was converted to $\mathrm{pH}$ by in vivo calibrations using the high $\mathrm{K}^{+}$-nigericin method [19]. As described above, the experiments were performed in $\mathrm{HCO}_{3}^{-}$free solution. Under these conditions the NHE-1 is the only alkalinizing mechanism active. NHE-1 activity was assessed by evaluating the rate of $\mathrm{pH}_{\mathrm{i}}$ recovery from an ammonium pre-pulse-induced acid load [20]. Transient ( $3 \mathrm{~min}$ ) exposure of myocytes to $20 \mathrm{mM} \mathrm{NH}_{4} \mathrm{Cl}$ was used for this purpose. Proton efflux $\left(\mathrm{J}_{\mathrm{H}}\right)$ was calculated as $\mathrm{dpH}_{\mathrm{i}} / \mathrm{dt} \times \beta_{\mathrm{i}}$ and comparison among different groups was done at a common $\mathrm{pH}_{\mathrm{i}}$ of 6.8 . The $\mathrm{dpH}_{\mathrm{i}} /$ $\mathrm{dt}$ at each $\mathrm{pH}_{\mathrm{i}}$ was obtained from an exponential fit of the recovery phase. $\beta \mathrm{i}$ is the intracellular buffering capacity of the myocytes and was measured by exposing cells to varying concentrations of $\mathrm{NH}_{4} \mathrm{Cl}$ in $\mathrm{Na}^{+}$-free HEPES bathing solution. $\beta \mathrm{i}$ at different levels of $\mathrm{pH}_{\mathrm{i}}$ were estimated from the least squares regression lines $\beta \mathrm{i}$ vs. $\mathrm{pH}_{\mathrm{i}}$ plots [21]. When used, the inhibitors were added to cells 10 minutes before $\mathrm{NH}_{4} \mathrm{Cl}$ exposure and remained present throughout the rest of the protocol.

\subsection{Measurement of ROS production}

Myocardial $\mathrm{O}_{2}^{-}$production was measured by the lucigeninenhanced chemiluminescence method in cardiac tissue slices from the left ventricle $(1 \times 5 \mathrm{~mm})$ as previously described [10]. Since high lucigenin concentrations ( $>20 \mu \mathrm{mol} / \mathrm{L}$ ) may favor redox cycling, we used $5 \mu \mathrm{mol} / \mathrm{L}$ lucigenin, at which the amount of artifacts has been proven insignificant [22]. For each intervention evaluated the lucigeninchemiluminescence signal in arbitrary units was normalized to milligrams of dry weight tissue per minute and

\subsection{Chemicals}

All drugs used in the present study were analytical reagent. Ang II, lucigenin $(5 \mu \mathrm{mol} / \mathrm{L})$ and 5 -HD $(100 \mu \mathrm{mol} / \mathrm{L})$, were purchased from Sigma; apocynin (300 $\mu \mathrm{mol} / \mathrm{L} ;$ Fluka); losartan (1 $\mu \mathrm{mol} / \mathrm{L} ;$ Merck); glibenclamide (50 $\mu \mathrm{mol} / \mathrm{L})$; RBI, USA) and cariporide $(10 \mu \mathrm{mol} / \mathrm{L}$ HOE642, kindly donated by Aventis Pharma). Either Krebs-HEPES buffer or dimethyl sulfoxyde (DMSO) were used to prepare drug dilutions. The final DMSO concentration, when used, was kept $<0.1 \%$.

\subsection{Statistics}

Results are expressed as mean \pm SEM. The Student $t$ test or 1 -way ANOVA followed by the Student-Newman-Keuls test were used when corresponding. Significance level was set at $P<0.05$.

\section{Results}

The effect of Ang II upon contractility was explored in isolated cat ventricular myocytes. Ang II induced a concentration-dependent increase in sarcomere shortening, reaching the maximal effect at a concentration of $100 \mathrm{nmol} / \mathrm{L}$ (Fig. 1). Since the positive inotropic effect

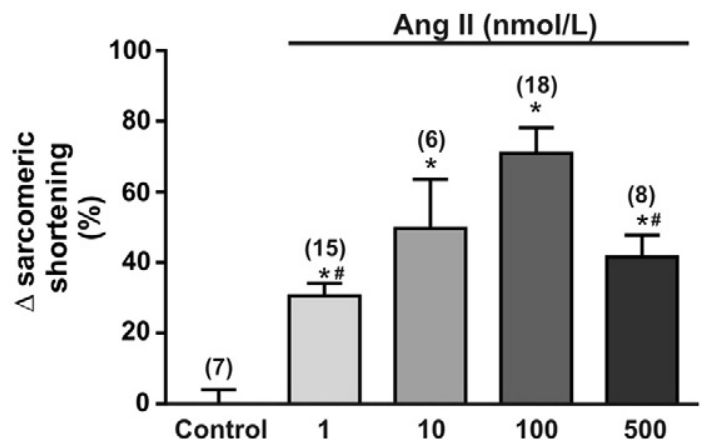

Fig. 1. Inotropic effect of different concentrations of Ang II in isolated cat cardiomyocytes. Note that the maximal effect upon sarcomere shortening was obtained with $100 \mathrm{nmol} / \mathrm{L}$ Ang II. Numbers between brackets denote the number of cardiomyocytes per experimental group. ${ }^{*}$ means $P<0.05$ vs. control, \# means $P<0.05$ vs. 100 nmol/L Ang; ANOVA 
induced by $500 \mathrm{nmol} / \mathrm{L}$ Ang II was lower than that observed with $100 \mathrm{nmol} / \mathrm{L}$, we decided to perform the rest of the experiments with the latter. An increase in sarcomere shortening of $70 \%$ compared to control cardiomyocytes was detected in the cardiomyocytes exposed to $100 \mathrm{nmol} / \mathrm{L}$ of the hormone (Fig. 2A and D). The blockade of the Ang II AT1 receptor with losartan was able to prevent the increase in sarcomere shortening induced by $100 \mathrm{nmol} / \mathrm{L}$ angiotensin II (Fig. 2B and D). Moreover, this positive inotropic effect seems to be partially mediated by activation of the NOX since apocynin was able to significantly reduce, although not abolish, it (Fig. 2C and D). As it has been already demonstrated NOX-dependent ROS are able to induce mitochondrial ROS production through a mKATP channel-dependent mechanism, phenomenon known as ROS-induced ROS release [7]. Therefore, the effect of two pharmacologically unrelated mKATP channel blockers (glibenclamide and 5-HD) upon Ang II-induced contractility was explored. Again, both compounds decreased Ang II positive inotropic response by approximately $50 \%$, remaining a similar portion of the contractility effect unchanged (Fig. 3). None of these inhibitors significantly affected contractility in control conditions $[111 \pm 3 \%(n=3)$ and $90 \pm 7 \%(n=5)$ vs. $100 \pm 5 \%(n=7)$, for glibenclamide, 5 -HD and control respectively]. This is interesting since under the same model it was previously shown that the positive inotropic effect induced by a lower concentration of Ang II ( $1 \mathrm{nmol} / \mathrm{L}$ ) can be completely prevented by the ROS scavenger MPG [N-(2-mercapto-propionyl)glycine]. It was also shown that the activation of the NHE-1 played a critical role in the increase in contractility by favoring the reverse mode of the NCX through the rise in intracellular $\mathrm{Na}^{+}$concentration. The NCX operating in its reverse mode introduces $\mathrm{Ca}^{2+}$ to the cytoplasm that impacts in force development. Therefore we explored the effect of NHE-1 inhibition on the positive inotropic effect of $100 \mathrm{nmol} / \mathrm{L}$ Ang II. Cariporide, a specific inhibitor of the NHE- 1 did not alter basal contractility $(104 \pm 6.8 \%$ vs. control, $n=$ 6); however it did partially reduce Ang II effect similarly to NOX and $\mathrm{mK}_{\text {ATP }}$ channel inhibitors (Fig. 3). In order to reinforce this result, we then investigated the influence of $100 \mathrm{nmol} / \mathrm{L}$ Ang II on NHE-1 activity by measuring $\mathrm{pH}_{\mathrm{i}}$. Steady-state $\mathrm{pH}_{\mathrm{i}}$ was slightly but significantly higher in cardiomyocytes exposed to $100 \mathrm{nmol} / \mathrm{L}$ Ang II compared to untreated controls (Fig. 4). Under this experimental condition-Krebs-HEPES
A
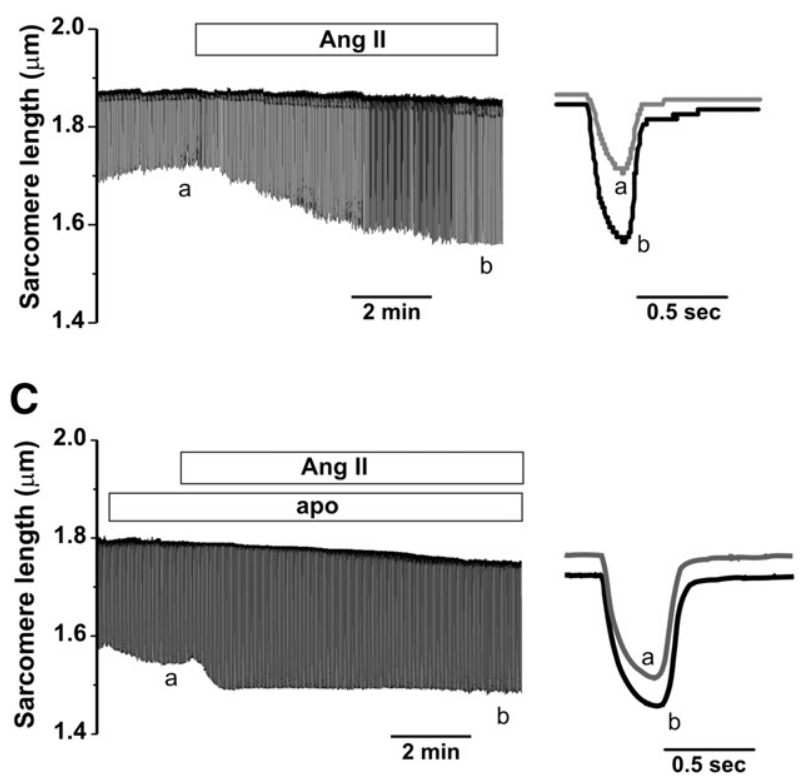

Ang II

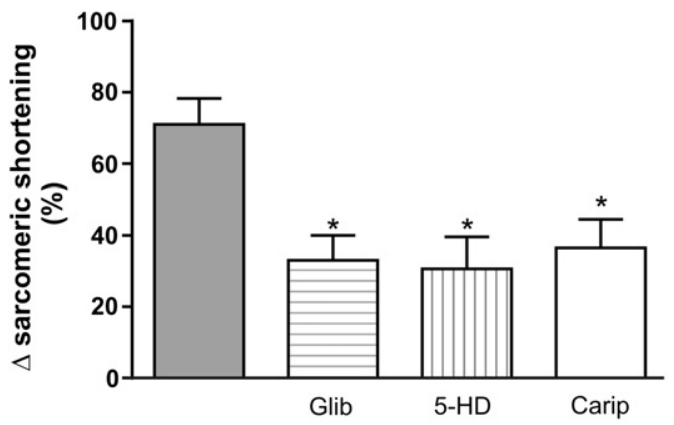

(18)
(5)
Fig. 3. The signaling pathway evoked by $100 \mathrm{nmol} / \mathrm{L}$ Ang II only partially depends on $\mathrm{mK}_{\text {ATP }}$ channel opening and NHE-1 activity. Both $\mathrm{mK}_{\text {ATP }}$ with glibenclamide (Glib) or 5-HD and NHE-1 inhibition with cariporide (Carip) significantly reduced the inotropic response to Ang II. However, a significant portion remained (approximately $50 \%$ ) supporting that another pathway was also involved. Numbers between brackets denote the number of cardiomyocytes per experimental group. * means $P<0.05$ vs. $100 \mathrm{nmol} / \mathrm{L}$ Ang II; ANOVA.

buffer with nominal absence of bicarbonate in the medium-the only active alkalinizing mechanism is the NHE-1, revealing the increase in steady-state $\mathrm{pH}_{\mathrm{i}}$ a stimulatory effect of Ang II upon the exchanger. To further explore this action we analyzed proton efflux during $\mathrm{pH}_{\mathrm{i}}$ recovery from an acute acid load in the presence and absence of $100 \mathrm{nmol} / \mathrm{L}$ Ang II. Fig. 5A shows representative recordings of $\mathrm{pH}_{\mathrm{i}}$ in cardiomyocytes transiently exposed to $\mathrm{NH}_{4} \mathrm{Cl}$ to induced intracellular acidosis. Similarly to the inotropic response, Ang II increased NHE-1-dependent proton efflux $\left(\mathrm{J}_{\mathrm{H}+}\right)$ through a NOX-dependent mechanism, since its stimulatory effect was completely prevented by inhibition of NOX with apocynin. Cardiomyocyte intrinsic buffering capacity relative to $\mathrm{pH}_{\mathrm{i}}$ was measured to calculate proton efflux through the NHE-1 (Fig. 5B). The average results of $\mathrm{J}_{\mathrm{H}+}$ are presented in Fig. 5C.

B
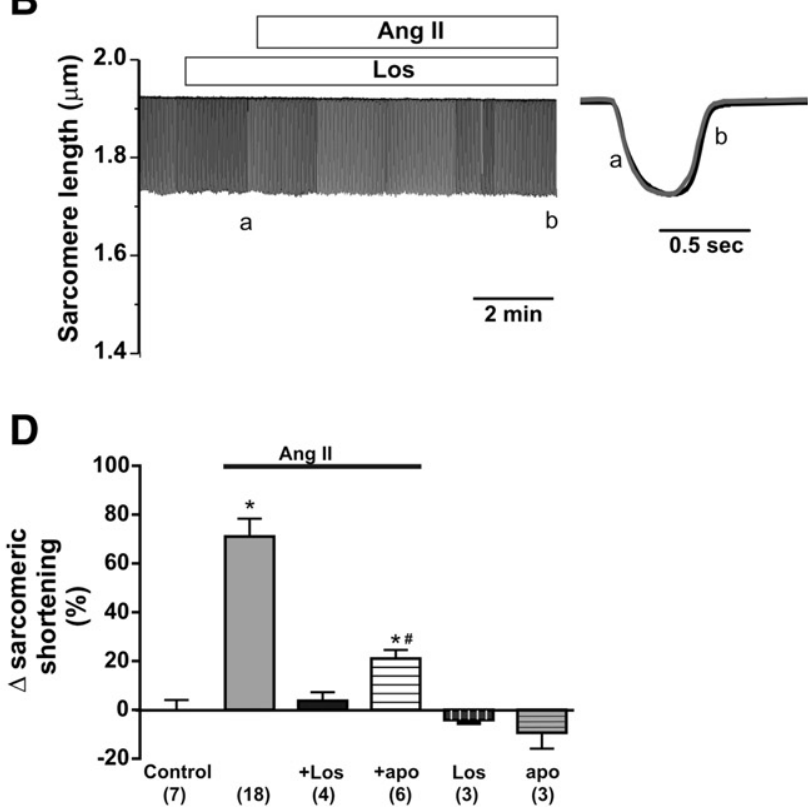

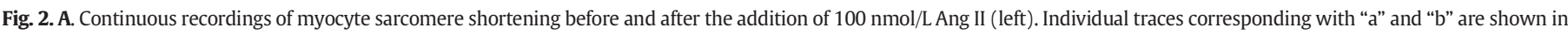

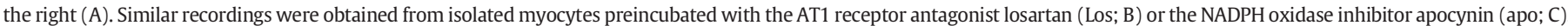

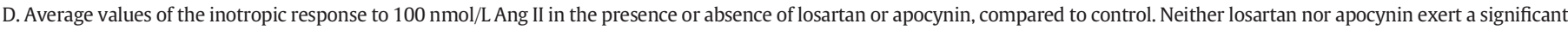

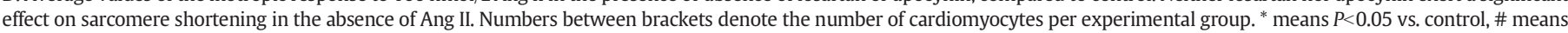
$P<0.05$ vs. $100 \mathrm{nmol} / \mathrm{L}$ Ang; ANOVA. 


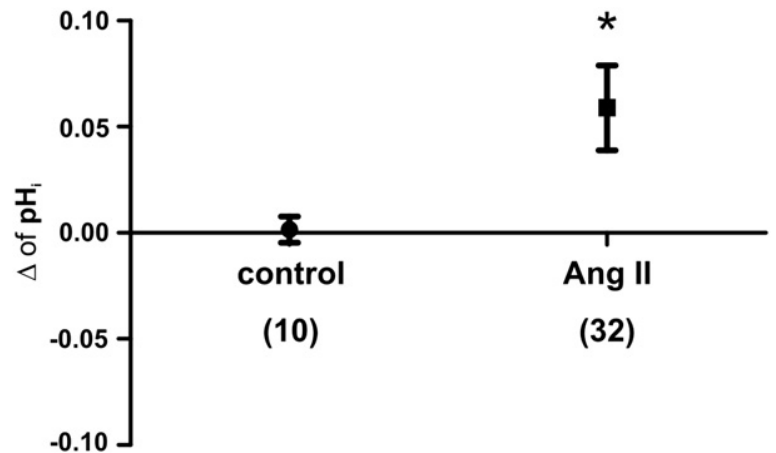

Fig. 4. Ang II (100 nmol/L) induced a slight but significant alkalization of isolated cardiomyocytes. Since intracellular $\mathrm{pH}\left(\mathrm{pH}_{\mathrm{i}}\right)$ recordings were performed in nominally absence of bicarbonate in the medium (Krebs-Hepes buffer) the rise in $\mathrm{pH}_{\mathrm{i}}$ should be attributed to an enhanced activity of the NHE-1 in the presence of Ang II. Numbers between brackets denote the number of cardiomyocytes per experimental group. * means $P<0.05$; t-test.

Finally, we explore the effect of $100 \mathrm{nmol} / \mathrm{L}$ Ang II on cat myocardial ROS production. Fig. 6 shows that $100 \mathrm{nmol} / \mathrm{L}$ Ang II increased ROS production, effect that was completely canceled not only by the specific blockade of Ang II AT1 receptor with losartan but also by NOX inhibition with apocynin or $\mathrm{mK}_{\mathrm{ATP}}$ blockade with glibenclamide or 5-HD. In order to explore the existence of a dose dependent response to Ang II on ROS production, similar to what is observed for sarcomere shortening, $1 \mathrm{nmol} / \mathrm{L}$ Ang II effect was also evaluated. This concentration of the peptide increased ROS production although to a significantly lower extent than $100 \mathrm{nmol} / \mathrm{L}$ Ang II (Fig. 6).

\section{Discussion}

The present study provides insight into the mechanism underlying the cardiomyocyte inotropic effect of Ang II in a concentration that it is not only the most widely used in the experimental arena but also the one that induces the greater contractility effect in isolated cat

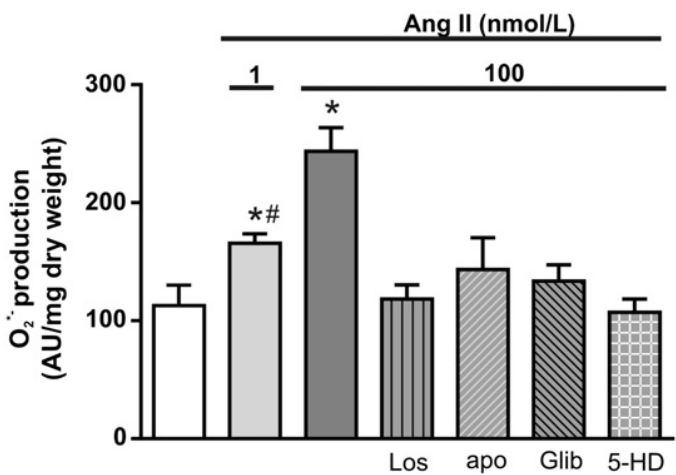

(22) (16)
(18) $\quad(4)$
(5) (3)

Fig. 6. Ang II dose-dependently increased myocardial superoxide $\left(\mathrm{O}_{2}{ }^{-}\right)$production. The effect of $100 \mathrm{nmol} / \mathrm{L}$ Ang II was further explored detecting that it was completely cancelled by AT1 receptor blockade with losartan (Los), NOX inhibition with apocynin (apo) and $\mathrm{mK}_{\text {ATP }}$ channel blockade with either glibenclamide (Glib) or 5-HD. Numbers between brackets denote the number of experiments per group. * means $P<0.05$ vs. control, \# means $P<0.05$ vs. $100 \mathrm{nmol} / \mathrm{L}$ Ang; ANOVA.

cardiomyocytes. Physiological plasma and myocardial tissue concentrations of Ang II have been reported to be in the $\mathrm{pmol} / \mathrm{L}$ to $\mathrm{nmol} / \mathrm{L}$ range; however it has been well demonstrated that during pathological conditions these concentrations significantly increase, reaching values even about a hundred of times higher [23]. We detected that $100 \mathrm{nmol} / \mathrm{L}$ Ang II, through activation of the AT1 receptors, induces NOX and mitochondrial-dependent ROS production responsible for approximately half of the increase in sarcomere shortening. Moreover, this concentration of the hormone also stimulates the NHE-1 probably through the same pathway, since the increase in NHE-1 activity was prevented by the NOX inhibitor apocynin.

The results presented herein constitute a relevant difference with the mechanism involved in the inotropic response to $1 \mathrm{nmol} / \mathrm{L}$ Ang II-a concentration in the range of that in the interstitial myocardium under physiological conditions [18]-that it has been previously described in detail elsewhere [6]. Under those circumstances both ROS
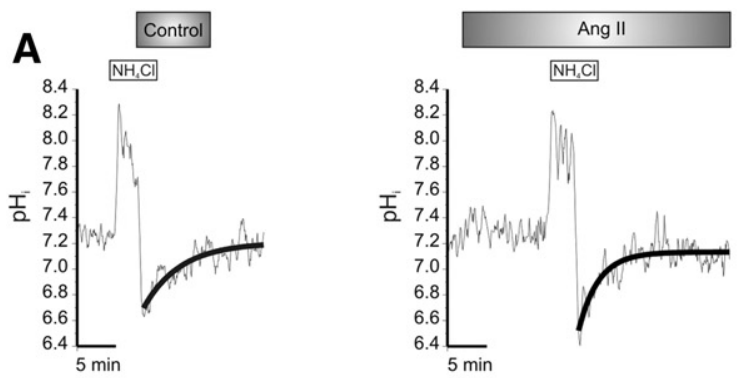

B
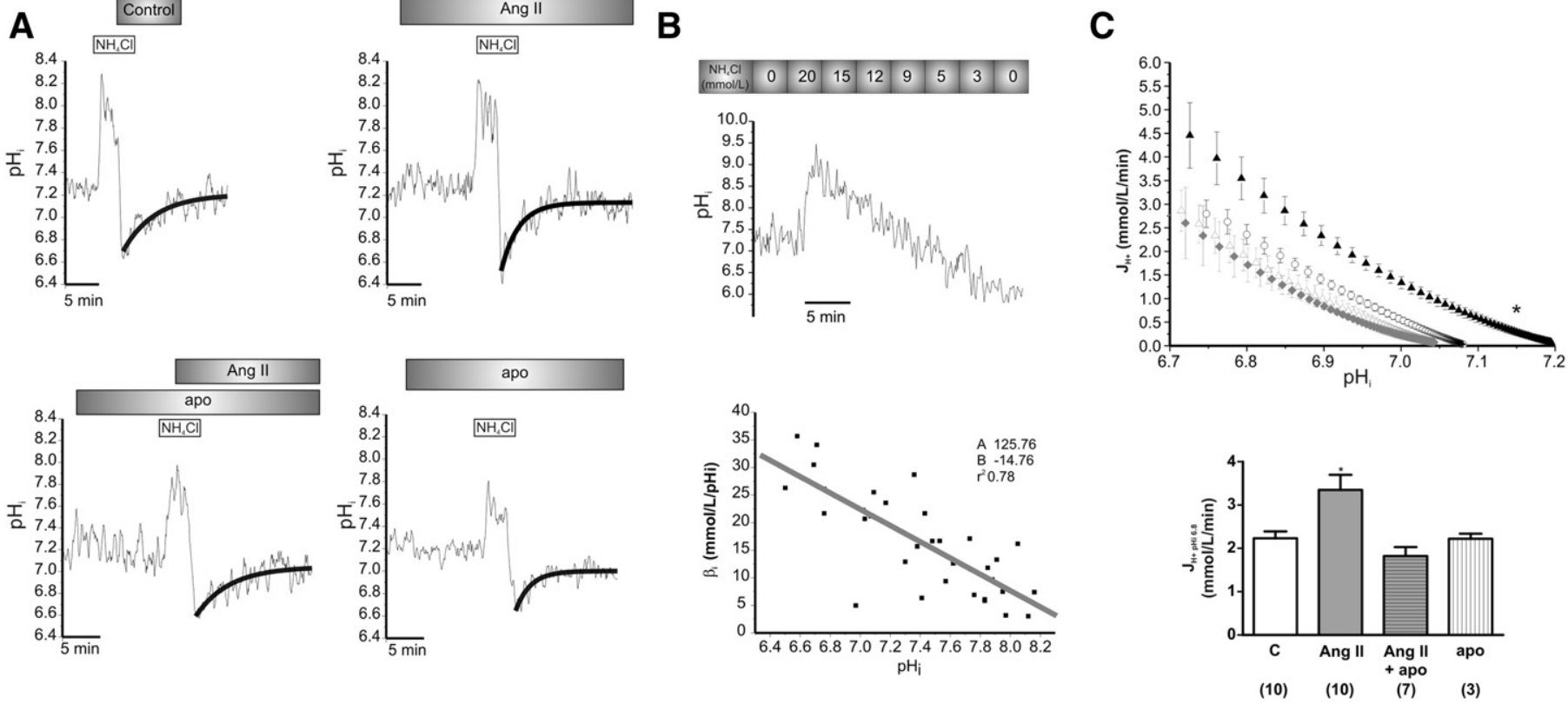

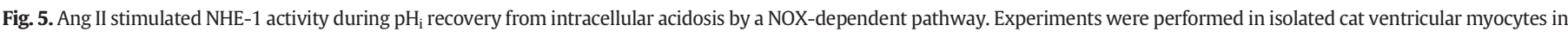

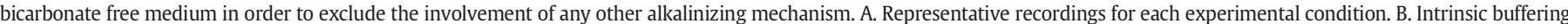

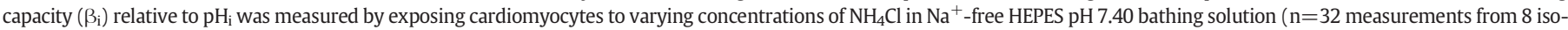

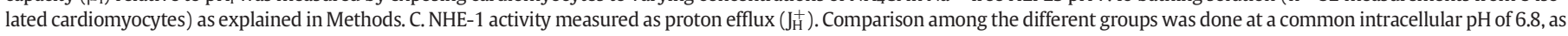
explained in Methods. Numbers between brackets denote the number of cardiomyocytes per experimental group. ${ }^{*}$ means $P<0.05$ vs. control: ANOVA. 
and NHE-1 appear to be strictly required to increase contractility. Furthermore, it has been already demonstrated that myocardial stretch shares the intracellular pathway evoke by $1 \mathrm{nmol} / \mathrm{L}$ exogenous Ang II to increase contractility [24]. Briefly, myocardial stretch induces AT1 receptor activation that through a chain of events leads to increased production of NOX-dependent mitochondrial ROS, activation of redoxsensitive kinases and stimulation of the NHE- 1 which finally increases $\mathrm{Na}^{+}$and consequently $\mathrm{Ca}^{2+}$ transient amplitude through the NCX operating in reverse mode.

In the case of higher Ang II concentrations (i.e.: $100 \mathrm{nmol} / \mathrm{L}$ ) it seems that at least two different pathways are activated leading to the inotropic response: one dependent on NOX/mitochondrial ROS production and NHE-1 activation (described above) and the other one being ROS/ NHE-1 independent. One possible mechanism involved in the latter could be an increase in L-type calcium current induced by PKC activation through $100 \mathrm{nmol} / \mathrm{L}$ Ang II [25]. Nevertheless, further research will be necessary to elucidate the intracellular events and final effectors involved in the latter.

Among NOX family members, NOX2 and NOX4 are the isoforms primarily expressed in cardiomyocytes (for review see Ref. [26]). While NOX2 is mainly localized in the cellular membrane and is sensitive to inhibition by apocynin, NOX4 has been recently described as primarily expressed in cardiac mitochondria; and it is not regulated either by apocynin or post-translational modifications [27]. The immediate product of NOX enzymes is $\mathrm{O}_{2}^{-}$, but because of both spontaneous and enzymatic dismutation $\mathrm{H}_{2} \mathrm{O}_{2}$ is also rapidly generated from this short-lived, unstable compound. We did not characterize the NOX isoform involved in the pathway leading to ROS formation; however, previous available evidence $[28,29]$ and the fact that apocynin suppressed ROS production in our study suggest that NOX2 is the isoform involved. With respect to the ROS-induced ROS released mechanism, although there is no conclusive data supporting that sarcolemmal NOX-derived ROS interacts with the mitochondria, Zhang et al. [30] using reconstituted $\mathrm{mK}_{\mathrm{ATP}}$ channels of bovine heart demonstrated that $\mathrm{O}_{2}^{-}$directly stimulates the opening of these channels. The opening of $\mathrm{mK}_{\mathrm{ATP}}$ channels would allow $\mathrm{K}^{+}$entry, mitochondrial swelling and increased ROS production/release $[9,31,32]$.

\section{Conclusions}

- Ang II exerts its maximal positive inotropic effect at the concentration $100 \mathrm{nmol} / \mathrm{L}$ in isolated cat ventricular myocytes.

- Different pathways underlie the increase in contractility induced by Ang II depending on the concentration of the hormone.

- The positive inotropic response to $100 \mathrm{nmol} / \mathrm{L}$ Ang II is due to both ROS/NHE-1 dependent and independent mechanisms, this being a point of divergence with the signaling triggered by lower concentrations of Ang II (i.e.: $1 \mathrm{nmol} / \mathrm{L}$ ).

\section{Acknowledgments}

This work was supported in part by grants PICT 2012-2907 from Agencia Nacional de Promoción Científica of Argentina and PIP 0433 from Consejo Nacional de Investigaciones Científicas y Técnicas of Argentina to Dr. Irene L Ennis.

\section{References}

[1] Madamanchi NR, Runge MS. Redox signaling in cardiovascular health and disease. Free Radic Biol Med 2013;61C:473-501.

[2] Lavigne MC, Malech HL, Holland SM, Leto TL. Genetic demonstration of p47phoxdependent superoxide anion production in murine vascular smooth muscle cells. Circulation 2001;104:79-84.

[3] Giordano FJ. Oxygen, oxidative stress, hypoxia, and heart failure. J Clin Invest 2005: 115:500-8.

[4] Kimura S, Zhang GX, Nishiyama A, Shokoji T, Yao L, Fan YY, et al. Role of $\mathrm{NAD}(\mathrm{P}) \mathrm{H}$ oxidase- and mitochondria-derived reactive oxygen species in cardioprotection of ischemic reperfusion injury by angiotensin II. Hypertension 2005:45:860-6.

[5] Hong HJ, Chan P, Liu JC, Juan SH, Huang MT, Lin JG, et al. Angiotensin II induces endothelin-1 gene expression via extracellular signal-regulated kinase pathway in rat aortic smooth muscle cells. Cardiovasc Res 2004;61:159-68.

[6] Cingolani HE, Villa-Abrille MC, Cornelli M, Nolly A, Ennis IL, Garciarena C, et al. The positive inotropic effect of angiotensin II: role of endothelin- 1 and reactive oxygen species. Hypertension 2006;47:727-34.

[7] Zorov DB, Filburn CR, Klotz LO, Zweier JL, Sollott SJ. Reactive oxygen species (ROS)induced ROS release: a new phenomenon accompanying induction of the mitochondrial permeability transition in cardiac myocytes. J Exp Med 2000;192:1001-14.

[8] Kimura S, Zhang GX, Nishiyama A, Shokoji T, Yao L, Fan YY, et al. Mitochondriaderived reactive oxygen species and vascular MAP kinases: comparison of angiotensin II and diazoxide. Hypertension 2005;45:438-44.

[9] Garciarena CD, Caldiz CI, Correa MV, Schinella GR, Mosca SM, Chiappe de Cingolani $\mathrm{GE}$, et al. $\mathrm{Na}+/ \mathrm{H}+$ exchanger-1 inhibitors decrease myocardial superoxide production via direct mitochondrial action. J Appl Physiol 2008;105:1706-13.

[10] Caldiz CI, Garciarena CD, Dulce RA, Novaretto LP, Yeves AM, Ennis IL, et al. Mitochondrial reactive oxygen species activate the slow force response to stretch in feline myocardium. J Physiol 2007;584:895-905.

[11] Cingolani HE, Perez NG, Aiello EA, de Hurtado MC. Intracellular signaling following myocardial stretch: an autocrine/paracrine loop. Regul Pept 2005;128:211-20.

[12] Avkiran M, Haworth RS. Regulatory effects of G protein-coupled receptors on cardiac sarcolemmal $\mathrm{Na}+/ \mathrm{H}+$ exchanger activity: signalling and significance. Cardiovasc Res 2003;57:942-52.

[13] Myers ML, Farhangkhoee P, Karmazyn M. Hydrogen peroxide induced impairment of post-ischemic ventricular function is prevented by the sodium-hydrogen exchange inhibitor HOE 642 (cariporide). Cardiovasc Res 1998;40:290-6.

[14] Rothstein EC, Byron KL, Reed RE, Fliegel L, Lucchesi PA. H(2)O(2)-induced Ca(2+) overload in NRVM involves ERK1/2 MAP kinases: role for an NHE-1-dependent pathway. Am J Physiol Heart Circ Physiol 2002;283:H598-605.

[15] Snabaitis AK, Hearse DJ, Avkiran M. Regulation of sarcolemmal $\mathrm{Na}(+) / \mathrm{H}(+)$ exchange by hydrogen peroxide in adult rat ventricular myocytes. Cardiovasc Res 2002;53:470-80

[16] Cingolani OH, Perez NG, Ennis IL, Alvarez MC, Mosca SM, Schinella GR, et al. In vivo key role of reactive oxygen species and NHE-1 activation in determining excessive cardiac hypertrophy. Pflugers Arch 2011;462:733-43.

[17] Wei S, Rothstein EC, Fliegel L, Dell'Italia LJ, Lucchesi PA. Differential MAP kinase activation and $\mathrm{Na}(+) / \mathrm{H}(+)$ exchanger phosphorylation by $\mathrm{H}(2) \mathrm{O}(2)$ in rat cardiac myocytes. Am J Physiol Cell Physiol 2001;281:C1542-50.

[18] Dell'Italia LJ, Meng QC, Balcells E, Wei CC, Palmer R, Hageman GR, et al. Compartmentalization of angiotensin II generation in the dog heart. Evidence for independent mechanisms in intravascular and interstitial spaces. J Clin Invest 1997;100: 253-8.

[19] Yeves AM, Garciarena CD, Nolly MB, Chiappe de Cingolani GE, Cingolani HE, Ennis IL. Decreased activity of the $\mathrm{Na}+/ \mathrm{H}+$ exchanger by phosphodiesterase $5 \mathrm{~A}$ inhibition is attributed to an increase in protein phosphatase activity. Hypertension 2010;56: $690-5$

[20] Camilion de Hurtado MC, Ennis IL, Perez NG, Chiappe de Cingolani GE, Morgan P. Cingolani HE. Upregulation of myocardial $\mathrm{Na}+/ \mathrm{H}+$ exchanger induced by chronic treatment with a selective inhibitor. J Mol Cell Cardiol 2002;34:1539-47.

[21] Zaniboni M, Swietach P, Rossini A, Yamamoto T, Spitzer KW, Vaughan-Jones RD. Intracellular proton mobility and buffering power in cardiac ventricular myocytes from rat, rabbit, and guinea pig. Am J Physiol Heart Circ Physiol 2003;285: H1236-46.

[22] Li Y, Zhu H, Kuppusamy P, Roubaud V, Zweier JL, Trush MA. Validation of lucigenin (bis-N-methylacridinium) as a chemilumigenic probe for detecting superoxide anion radical production by enzymatic and cellular systems. J Biol Chem 1998; 273:2015-23.

[23] Sadoshima J, Xu Y, Slayter HS, Izumo S. Autocrine release of angiotensin II mediates stretch-induced hypertrophy of cardiac myocytes in vitro. Cell 1993;75:977-84.

[24] Cingolani HE, Perez NG, Cingolani OH, Ennis IL. The Anrep effect: 100 years later. Am J Physiol Heart Circ Physiol 2013;304:H175-82.

[25] Aiello EA, Cingolani HE. Angiotensin II stimulates cardiac L-type $\mathrm{Ca}(2+)$ current by a $\mathrm{Ca}(2+)$ - and protein kinase C-dependent mechanism. Am J Physiol Heart Circ Physiol 2001;280:H1528-36.

[26] Maejima Y, Kuroda J, Matsushima S, Ago T, Sadoshima J. Regulation of myocardial growth and death by NADPH oxidase. J Mol Cell Cardiol 2011;50:408-16.

[27] Ago T, Kuroda J, Pain J, Fu C, Li H, Sadoshima J. Upregulation of Nox4 by hypertrophic stimuli promotes apoptosis and mitochondrial dysfunction in cardiac myocytes. Circ Res 2010;106:1253-64

[28] Griendling KK. Novel NAD(P)H oxidases in the cardiovascular system. Heart 2004; 90:491-3.

[29] Zhang M, Kho AL, Anilkumar N, Chibber R, Pagano PJ, Shah AM, et al. Glycated proteins stimulate reactive oxygen species production in cardiac myocytes: involvement of Nox2 (gp91phox)-containing NADPH oxidase. Circulation 2006;113: $1235-43$.

[30] Zhang DX, Chen YF, Campbell WB, Zou AP, Gross GJ, Li PL. Characteristics and superoxide-induced activation of reconstituted myocardial mitochondrial ATPsensitive potassium channels. Circ Res 2001;89:1177-83.

[31] Costa AD, Quinlan CL, Andrukhiv A, West IC, Jaburek M, Garlid KD. The direct physiological effects of mitoK(ATP) opening on heart mitochondria. Am J Physiol Heart Circ Physiol 2006;290:H406-15.

[32] Wang W, Fang H, Groom L, Cheng A, Zhang W, Liu J, et al. Superoxide flashes in single mitochondria. Cell 2008;134:279-90. 